\title{
Integrated Information Exchange for Logistics Systems based on Internet of Things
}

\section{Sajad Bagherian Marzouni', Hamed Fazlollahtabar ${ }^{2 *}$ and Iraj Mahdavi'}

${ }^{1}$ Department of Industrial Engineering, Mazandaran University of Science and Technology, Babol, Iran

${ }^{2}$ Department of Industrial Engineering, School of Engineering, Damghan University, Damghan, Iran

\begin{abstract}
Logistics system is a significant and complicated process for manufacturers. Logistics systems begin with raw materials provision, product design and assembly, and distribution to customers. To conceptualize this process a supply chain can be considered. Therefore, supply chain modeling and optimization with respect to different process of logistics system and the corresponding data transaction are major challenges. On the other hand, advances in digital environment in logistics systems are merged with the evolution of industry 4.0 that includes internet of things (IOT), big data, cloud computing and information systems. Hence, this paper concerns with developing information systems for different processes of logistics systems in modeling data exchange among the elements of supply chain. Big data notion and cloud computing are considered in proposing information flow mechanism. The findings provide a comprehensive data interchange amongst elements of an intelligent logistics system in the platform of internet. In different stages of the proposed logistics system production, transportation, inventory and distribution functions and decisions are proposed. The required data flow is designed through database concepts for real time decision making.
\end{abstract}

\section{Keywords}

Industry 4.0, Logistics systems, Big data, Management information systems

\section{Introduction}

In recent era, investigators have been faced important challenges in terms of technological revolutions. Indeed, intelligent machines and robots, Cyber-Physical Systems (CPS), Internet of Things (IoT), Big Data, virtual industrialization and Smart Factories are creating new possible futures in terms of society [1,2]. The fourth industrial revolution with the general introduction of a set of new devices, processes, and technological tools was streamed but not well integrated [1,3]. By the evolution of industry 4.0 and the related technologies the logistics systems are smarter and more flexible to adopt real time data and the corresponding decisions. By the way, coordination among all elements of the logistics system should be so that to be able to handle such dynamic environment. Thus, we aim to integrate the process

\footnotetext{
*Corresponding author: Hamed Fazlollahtabar, Department of Industrial Engineering, School of Engineering, Damghan University, Damghan, Iran

Accepted: November 19, 2018; Published: November 21, 2018

Copyright: (C) 2018 Marzouni SB, et al. This is an open-access article distributed under the terms of the Creative Commons Attribution License, which permits unrestricted use, distribution, and reproduction in any medium, provided the original author and source are credited.

Marzouni et al. Int J Robot Eng 2018, 3:011
} 
and categorize the factors and functions of each element in any stages. Also, to relax the challenges of data flow and deposit, internet of things, big data, and cloud environment are employed.

The remainder of the paper is organized as follows. Next, the state of the art is reviewed. In Section 3, the information flow for a logistics system is developed. In Section 4, the proposed integrated model in the platform of internet of things is illustrated and the required functions are reported. We conclude in Section 5.

\section{State of the Art}

The keyword "Industry 4.0" means a development that made changes on traditional industries essentially [4]. As far as the field of logistics is concerned, major implications are predicted, too. In fact, logistics represents an appropriate application area for Industry 4.0 [5]. The integration of CPS and IoT into logistics promises to enable a real-time tracking of material streams, improved transport forwarding and accurate risk management, to mention but a few prospects. In fact, it can be argued that industry 4.0 in its pure perspective can only become reality if the logistics is able to provide production systems with input factors needed at the right time, in the right quality and in the right place.

In addition, industrial companies are facing the new challenges in terms of increasing individualization of products, the need to increase the resource effectiveness and reducing marketing time. These problems are faced in particular with increasing digitization, IT penetration and networking of products, manufacturing resources and processes. The concepts are often classified under the name "industry 4.0" [6].

According to the services industry, the dominant logic, with the focus on adapting traditional engineering approaches to the service sector, leads to the emergence of an official approach to service engineering [7]. In this term, some authors call it a "servitization" process [8,9].

Virtual Manufacturing (VM) introduced the concept of manufacturing process simulation using special computing environments, but the production plan was still connected to the product, which added a business model [10]. The recent models of the Internet of Industry (Industry 4.0) can ultimately integrate the business process and production, and fully express the concept of the product/service, which is based on physical-cyber production systems $[2,11]$.

loT offers new possibilities for performance. For example, road transport trucks can be automatically controlled by the host's profile, which will allow them to work at predefined intervals at standard speeds to increase fuel economy. Daimler Group has invested in the development of mobile services such as car2go, myTaxi or moovel; General Electric has also invested in systems for launching and operating equipment, and factories have been using the "Industrial Design" system (the Internet industry) use [12].

Using the loT, it is possible to monitor the travel process of packages and letters. Continuous monitoring and control the possibility of solving the question "Where is the package?" gives. In case of delay, the client can be notified before the consequences and consequences.

In the case of storage in warehouses, intelligent shelving and smart pallets will become the driving force behind modern financial management. In terms of freight transportation, tracking and tracking is quicker, more accurate, predictable and secure. Analysis of the development of a "connected fleet" can help predict failure and automatically plan currents aimed at improving the supply chain.

Also, Big Data has a potential value that has not yet been discovered. Nevertheless, it has been observed that "every constructor has an unbelievable amount of data that has never been used. They literally drown in it, and when it begins to assemble it, it breaks down and Analyzing it and linking it to business results, they are amazed at what they are leaving" [13]. Several researchers worked on the applications of big data. Chen, et al. developed the concept of big data in business intelligence [14]. Dubey, et al. investigated the sustainability in manufacturing using big data [15]. Song, et al. studied the performance evaluation in big data environment [16]. Wamba and Akter [17] analyzed the literature for big data in supply chain management. Wang, et al. studied logistics system for research and applications for big data [18]. Generally, researchers tried to study different dimensions of Big Data and gain potential benefits for supply chain management (SCM). Understanding the role of Big Data in increasing the efficiency and profitability of a company to supply chain managers is important. 


\section{A Logistics System Overview}

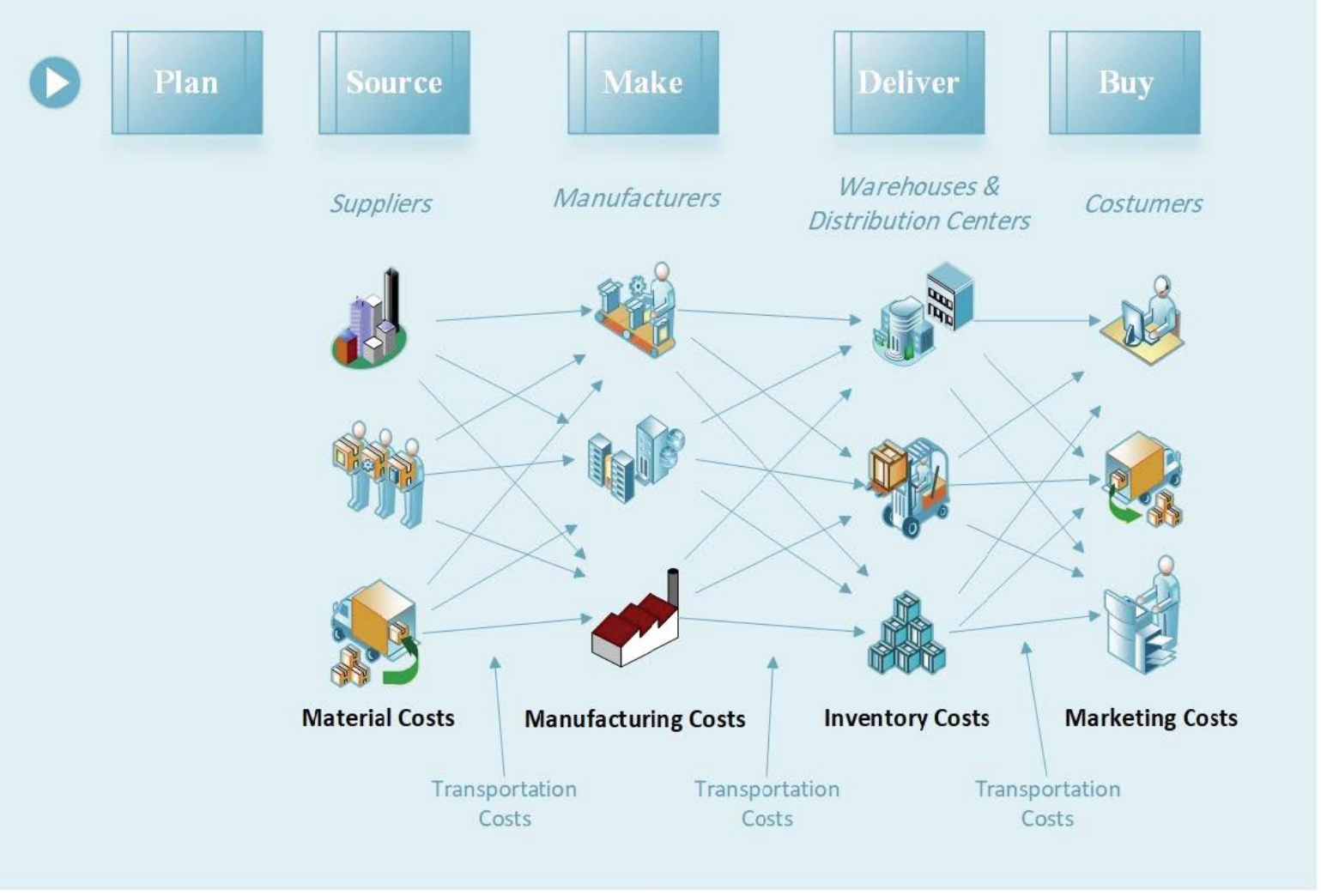

Figure 1: An overview of information flow in logistics systems.

\section{Information Flow of Logistics Systems}

The supply chain design is a related decision process that aims to define appropriate configuration and efficient management strategies for these systems. In addition, in order to help understand the logistics system's operation and how it is structured and organized in a hierarchy, and the ability to balance and plan, several aspects of this process, such as nutrition, equipment selection, ergonomic risk and learning effects.

For a generic logistics system including multiple layers such as supplier, producer, distributor, retailor and customer the impacts of internet can be considered. The information flow between any two layers of the logistics system influences the decision making. Decisions are significant for improving the performance and increase the productivity. An overview of a logistics system is shown in Figure 1.

In Figure 1, we have the logistics system information flow that includes ordinary logistics parts. In first stage we have Plane that means before any action we should make ready a plan in order to optimize our logistics stages. After that we have source, it represents that suppliers should determine materials in the way of decreasing side effects of material costs, also this source will effect on manufacturers in next step. In make stage with respect to suppliers and material costs will specify manufacturing costs, also in deliver stage warehouses and distribution centers with respect to make stage, will specify inventory costs and will influence on costumers in buy stage.

As shown in the proposed logistics system, we consider 5 main stages that each stage contains multiple choices due to multiple factor consideration. These factors show that in each stage several partners exist, i.e. in source stage several enterprises are active in material provision. In addition, between all of the system stages the information exchange showed by arrows; this information exchange between each stage happen continuously, between source and make stage the information of suppliers deliver to manufactures; so on between make stage and deliver stage the 
information of manufacturers deliver to distribution centers and similarly between deliver stage and buy stage the information of distribution centers deliver to costumers. The type of information that is exchanged between stages will be different, i.e. between make and deliver stage, the information such as production type, number of products and quality measures will deliver to distribution centers.

For all of material flows in logistics system we consider transportation costs and its side effects to obtain optimal decision effectively. Also, we recognize that in most of the actions and reactions of this logistics flow we can use loT base information systems. In order to this subject we should attend that The loT-based information flow system can be used in most of the actions and responses of this logistics stream. In most companies in the logistics and transportation sectors, there is a need to use the Internet-based termination of objects, in fact, the Internet will improve the supply chain objects. IoT will help companies increase their safety and impact levels. Key technologies in the implementation of the Internet are objects of Wi-Fi connectivity, security sensors, and NFC communications (near field communications). One of the concerns is privacy and information security, which could be seen as the biggest obstacle in implementing loT solutions. Also, the high level of complexity of these solutions is important as a high performance risk.

\section{Integrated IoT-Logistics System}

In this research, an intelligent logistics information flow system is designed based on Internet of Things (IoT). In fact, elements of logistics system are considered as things having data exchange for operations management and optimization purposes. As shown in Figure 2, operations and decisions in logistics system are categorized in several items to be process using data extracted from the elements. Operations are divided into production, transportation, inventory and distribution each has some sub-operations. For instance, production is composed of machines and equipment that are interconnected using $\mathrm{Wi}$ $\mathrm{Fi}$ technology to exchange data. Also, production processes are monitored in an online web system. On the other hand, decisions are based on the optimization performed using the operational data. Mostly used decisions in supply chain are production

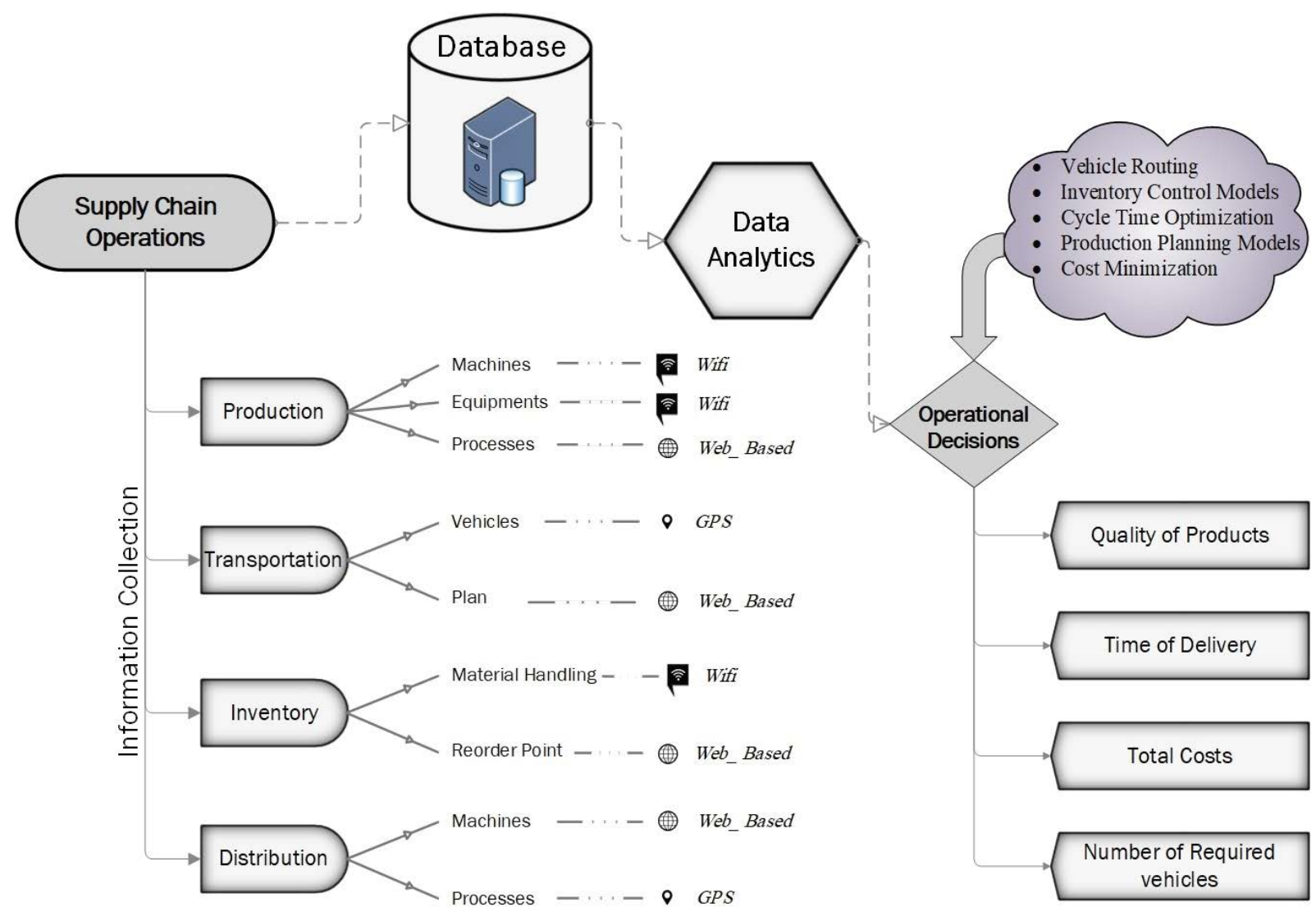

Figure 2: An loT based logistics system. 
planning, inventory control, vehicle routing, cost analysis and time management. Intelligent data transfer among operation and decisions elements lead to effective decisions.

As a complex integrated system, loT complement various devices with sensor capabilities, identification, processing, communications, and network integration. An loT system includes Industrial Wireless Networks (IWN) and Internet of Things (IoT). This includes automation tools, networks, cloud computing and terminals. An IoT system is provided by providing specific and personalized products. Users can customize products through web pages. Then, web servers direct information through wired or wireless networks to clouds and industrial plants. In order to get information, the designer integrates the design, and optimizes, manages and monitors the production process based on the products manufactured effectively. With the help of selfoptimizing decision making machinery, machinery and equipment to improve performance will be further developed. Since the production and supply are dynamic, the life cycle of a product is also variable. With regard to changes, decentralization, self-optimization, and automation, they can contribute more effectively and effectively to the dynamic process.

Technologies that are employed in the proposed loT-based supply chain are Wi-Fi for data exchange in production operation, web service for inventory data collection and GPS that is used in vehicle routing for location determination purpose. In Figure 3, a configuration of technologies and the corresponding operations of supply chain are presented.

With respect to the propose configuration of SCM that could be very complex when multiple products in multi periods exist. To handle such a huge amount of information specific paradigms and concepts need to be considered. To handle this Big Data notion and models are investigated.

Among the supply system, information sources are retailers, shipping, invoices, and more. Customer profile data, social networking profiles, orders, market forecasts, and geographic plans are substantial. By using customer data to analyze information from the delivery system, retailers can meet their customer expectations by predicting their behavior.

\section{Conclusions}

Within this paper, we showed that the fourth industrial revolution can be viewed as a change in the production logic of an increasingly decentralized, self-regulating value creation, capability by concepts and technologies such as CPS, IoT, Big Data, mass calculation, or incremental production, and Smart factories are best described

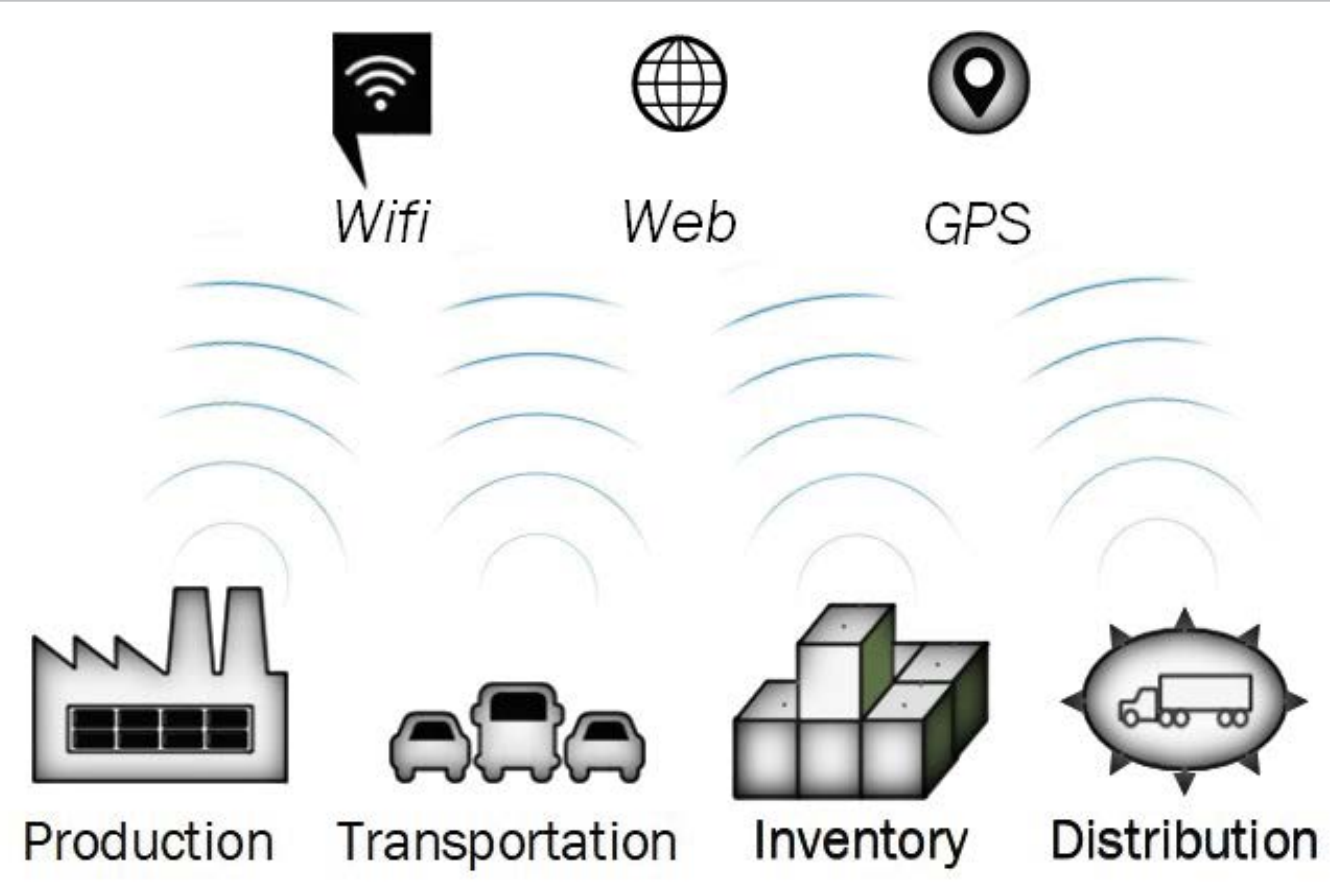

Figure 3: Technologies being used in loT-based logistics systems. 
to help companies meet their future production needs. It also provides an overview of the impact that the fourth industrial revolution has on the design and management of the supply chain. In addition, we proposed that companies should be supported in their work in industry 4.0. This can be achieved through the concepts and frameworks that illustrate the various industry blocks and dimensions of the 4.0 industry and may thus act as a guide for guidance.

For future researches, the following could be investigated:

- With respect to the elements and function and their corresponding decisions, mathematical models could be developed as a decision aid;

- Database clustering and data mining can be embedded through cloud environment for faster processing;

- Integrated multi-objective mathematical model can be formulated for overall decision making in the proposed integrated loT- based logistics system.

\section{References}

1. Blanchet $M$, Rinn $T$, Von Thaden $G$, De Thieulloy $G$ (2014) Industry 4.0: The new industrial revolutionHow Europe will succeed. Hg. v. Roland Berger Strategy Consultants $\mathrm{GmbH}$. München.

2. Hermann M, Pentek T, Otto B (2016) Design principles for industry 4.0 scenarios. $49^{\text {th }}$ Hawaii International Conference on System Sciences (HICSS).

3. Wahlster W (2012) Industry 4.0: From smart factories to smart products. Paper presented at the Forum Business Meets Research BMR.

4. Rennung F, Luminosu CT, Draghici A (2016) Service provision in the framework of industry 4.0. ProcediaSocial and Behavioral Sciences 221: 372-377.

5. Bauernhansl T, Ten Hompel M, Vogel-Heuser B (2014) Industrie 4.0 in Produktion, Automatisierung und Logistik: Anwendung, Technologien und Migration. Springer.

6. Lachenmaier JF, Lasi H, Kemper HG (2015) Entwicklung und Evaluation eines Informationsversorgungskonzepts für die Prozess-und Produktionsplanung im Kontext von Industrie 4.0. In: Thomas O, Teuteberg F, Proceedings der 12. Internationalen Tagung Wirtschaftsinformatik, Osnaburk, S1-S15.
7. Qiu RG (2014) Service science: The foundations of service engineering and management. John Wiley \& Sons.

8. Baines T (2015) Exploring service innovation and the servitization of the manufacturing firm. ResearchTechnology Management 58: 9-11.

9. Schmenner RW (2009) Manufacturing, service, and their integration: Some history and theory. International Journal of Operations \& Production Management 29: 431-443.

10. Van der Aalst WMP, Arthur HM ter Hofstede, M Weske (2003) Business process management: A survey. LNCS, 1-12.

11. Brettel $M$, Friederichsen $N$, Keller $M$, Rosenberg $M$ (2014) How virtualization, decentralization and network building change the manufacturing landscape: An Industry 4.0 Perspective. International Journal of Mechanical, Industrial Science and Engineering 8: 37-44.

12. Perera C, Ranjan R, Wang L, Khan SU, Zomaya AY (2015) Big data privacy in the internet of things era. IT Professional 17: 32-39.

13. Records R, Fisher Q (2014) Manufacturers connect the dots with Big Data and analytics. Computer Science Corporation 1-6.

14. Chen H, Chiang RH, Storey VC (2012) Business intelligence and analytics: From big data to big impact. MIS quarterly, 1165-1188.

15. Dubey R, Gunasekaran A, Childe SJ, Wamba SF, Papadopoulos T (2016) The impact of big data on world-class sustainable manufacturing. The International Journal of Advanced Manufacturing Technology 84: 631-645.

16. Song ML, Fisher R, Wang JL, Cui LB (2016) Environmental performance evaluation with big data: Theories and methods. Annals of Operations Research 459-472.

17. Wamba SF, Akter S (2015) Big data analytics for supply chain management: A literature review and research agenda. Paper presented at the Workshop on Enterprise and Organizational Modeling and Simulation, 61-72.

18. Wang G, Gunasekaran A, Ngai EW, Papadopoulos T (2016) Big data analytics in logistics and supply chain management: Certain investigations for research and applications. International Journal of Production Economics 176: 98-110. 